\title{
Research criteria for the diagnosis of prodromal dementia with Lewy bodies
}

Ian G. McKeith, F Med Sci, MD, Tanis J. Ferman, PhD, Alan J. Thomas, PhD, Frédéric Blanc, MD, Bradley F. Boeve, MD, Hiroshige Fujishiro, MD, Kejal Kantarci, MD, MS, Cristina Muscio, PhD, John T. O'Brien, F Med Sci, DM, Ronald B. Postuma, MD, MSc, Dag Aarsland, PhD, Clive Ballard, MD, Laura Bonanni, MD, PhD, Paul Donaghy, PhD, Murat Emre, MD, James E. Galvin, MD, MPH, Douglas Galasko, MD, Jennifer G. Goldman, MD, MS, Stephen N. Gomperts, MD, PhD, Lawrence S. Honig, MD, PhD, Manabu Ikeda, MD, PhD, James B. Leverenz, MD, Simon J.G. Lewis, MD, Karen S. Marder, MD, MPH, Mario Masellis, MD, PhD, David P. Salmon, PhD, John Paul Taylor, MB, BS, PhD, Debby W. Tsuang, MD, Zuzana Walker, MD, and Pietro Tiraboschi, MD, for the prodromal DLB Diagnostic Study Group

Neurology ${ }^{\circledR}$ 2020;94:743-755. doi:10.1212/WNL.0000000000009323

\begin{abstract}
The prodromal phase of dementia with Lewy bodies (DLB) includes (1) mild cognitive impairment (MCI), (2) delirium-onset, and (3) psychiatric-onset presentations. The purpose of our review is to determine whether there is sufficient information yet available to justify development of diagnostic criteria for each of these. Our goal is to achieve evidence-based recommendations for the recognition of DLB at a predementia, symptomatic stage. We propose operationalized diagnostic criteria for probable and possible mild cognitive impairment with Lewy bodies, which are intended for use in research settings pending validation for use in clinical practice. They are compatible with current criteria for other prodromal neurodegenerative disorders including Alzheimer and Parkinson disease. Although there is still insufficient evidence to propose formal criteria for delirium-onset and psychiatric-onset presentations of $\mathrm{DLB}$, we feel that it is important to characterize them, raising the index of diagnostic suspicion and prioritizing them for further investigation.
\end{abstract}

\section{Introduction}

Dementia with Lewy bodies (DLB) accounts for $7 \cdot 5 \%$ or more of all dementias in older people. ${ }^{1}$ It is characterized by dementia together with varying combinations of the core clinical features of parkinsonism, REM sleep behavior disorder (RBD), fluctuating cognition/alertness, and visual hallucinations. ${ }^{2}$ There is a variable progression of $\alpha$-synuclein aggregation many years before the full DLB syndrome develops, ${ }^{\mathrm{e} 1}$ which likely determines the pattern of early clinical changes. Prodromal DLB refers to a predementia stage with signs or symptoms indicating that DLB will subsequently develop and encompasses not only cognitive deficits but also a variable mixture of noncognitive clinical features including motor symptoms and signs, sleep disorders, autonomic dysfunction, and neuropsychiatric disturbance. ${ }^{3}$ Because these first clinical manifestations can occur 15 years or more before dementia onset, precise early diagnosis of DLB presents particular challenges, individuals being extremely difficult to distinguish from those with the first manifestations of Parkinson disease (PD) or multiple system atrophy (MSA), which are also $\alpha$-synuclein-related syndromes, ${ }^{4}$ or of other dementing disorders, particularly Alzheimer disease (AD).

\author{
Correspondence \\ Dr. McKeith \\ i.g.mckeith@ncl.ac.uk
}




\section{Glossary}

AD = Alzheimer disease $;$ DAT $=$ dopamine transporter; DLB $=$ dementia with Lewy bodies; FTD = frontotemporal dementia; MCI = mild cognitive impairment; MCI-LB = MCI with Lewy bodies; MIBG = meta-iodobenzylguanidine; $\mathbf{M S A}=$ multiple system atrophy; NCD = neurocognitive disorder; PD = Parkinson disease; PSG = polysomnography; QEEEG = Quantitative EEG; RBD = REM sleep behavior disorder; RSWA = REM sleep without atonia; VH = visual hallucination; VRH = ventilatory response to hypercapnia.

Reliable identification of prodromal DLB would enable early intervention while pathologic burden is circumscribed and before clinical symptoms become debilitating. It would assist clinicians to streamline care, anticipate treatment options known to be effective in DLB, ${ }^{\mathrm{e} 2}$ and to avoid or minimize iatrogenic adverse events with the goal of fewer office and emergency department visits. ${ }^{\mathrm{e} 3}$ Importantly, early diagnosis would help patients and families to plan and to implement early nonpharmacologic interventions, (e.g., exercise and behavioral strategies). It would also facilitate selection for trials of targeted therapies as these become available.

\section{Methods}

We performed electronic searches of MEDLINE, PubMed, and EMBASE databases using the combination of a number of medical subject headings, Emtree subject headings, and freetext terms ("dementia with Lewy bodies", "Lewy body dementia", "Lewy body disease", "prodromal", "delirium", "psychosis", "mild cognitive impairment", "rapid eye movement sleep behavior disorder" for clinical categories, and "neuropsychological test", "dopamine transporter imaging", "positron emission tomography", "meta-iodobenzylguanidine myocardial scintigraphy", "nuclear magnetic resonance imaging", "electroencephalography", "cerebrospinal fluid", "rapid eye movement sleep without atonia" for biomarkers). All relevant articles were retrieved, placing restrictions on fields (free-text terms searched exclusively in the title or abstract of the articles) and date (last 5 years). Except for book chapters, all publication types (original articles, reviews, editorials, and letters) were considered. Because the focus of this review was on prodromal DLB, studies on the broader, less specific category of Lewy body disease (which comprises both DLB and PD) were also considered. We then used Refworks to remove duplicates and share the resulting 3570 records among the lead authors. Of all fulltext articles assessed for eligibility after the abstract screening phase, those eventually included either as listed or as e-references were selected based on their relevance (data available from Dryad, e-references, doi:10.5061/dryad. $1 \mathrm{c} 59 \mathrm{zw} 3 \mathrm{rv})$. Seminal papers on the topic were included regardless of publication date. The preliminary findings and recommendations were presented for discussion and feedback at a session of the International Lewy Body Dementia Conference in Las Vegas, NV, USA, in June 2019, following which further revision and review took place.

\section{How does prodromal DLB usually present?}

One or more of the core clinical features characteristic of fully developed DLB may develop before dementia and are usually accompanied by mild cognitive complaints. ${ }^{5}$ Spontaneous parkinsonism often develops within the predementia stage but is not present in all patients. ${ }^{3,6} \mathrm{RBD}$ is a parasomnia that typically occurs years, and even decades, before the onset of dementia or parkinsonism and may presage any of the $\alpha$-synucleinopathies. ${ }^{4,7, e 4}$ In patients with mild cognitive deficits who later develop dementia, both parkinsonism and RBD strongly predict a later transition to DLB rather than to $\mathrm{AD}$ or other dementia types. ${ }^{6,8}$ Delirium can occur during the predementia stage of $\mathrm{DLB}^{9}$ as can fluctuations of cognition and $\operatorname{arousal}^{3}$ that may give rise to a diagnosis of delirium. Visual hallucinations (VHs) either spontaneous or provoked by illness or medication are more likely to occur compared with normal controls or prodromal $\mathrm{AD} .^{10,11}$ There are also case reports of delusions, hallucinations, depression, and anxiety as presenting features of DLB. ${ }^{12}$ Based on such observations, 3 prototypic prodromal DLB syndromes have been proposed ${ }^{13}$ as (1) mild cognitive impairment (MCI), (2) delirium-onset, or (3) psychiatric-onset.

\section{$\mathrm{MCl}$ with Lewy bodies}

The National Institute on Aging and Alzheimer's Association criteria for $\mathrm{MCI}^{14, \text { es }}$ provide a standardized approach to diagnosis and form the basis for our proposed MCI with Lewy body (MCI-LB) criteria. They require a cognitive complaint from the patient or from an informant or clinician who knows them and has observed a decline. Also required are deficits in one or more cognitive domains that are greater than would be expected from normal aging, do not represent lifelong patterns of lower cognitive function, and are not associated with acute medical or neurologic insults. Although people with MCI may be less efficient or less capable at performing tasks they have performed previously, their cognitive deficits should not be sufficient to interfere with their typical daily functioning. In other words, there should be an overall preservation of their prior level of independence with minimal interference in day-to-day functional abilities, which, by definition, does not constitute a dementia.

Objective cognitive impairment is optimally based on standardized assessment with scores on neuropsychological measures that are typically 1 to 1.5 SDs below the mean for their age and education matched peers on culturally appropriate normative data (i.e., for the impaired domain(s), when available). It is emphasized that these ranges are guidelines 
and not cutoff scores. ${ }^{14}$ Impairment on neuropsychological tests may also be demonstrated by significant decline demonstrated on serial testing or significant decline from estimated premorbid abilities. ${ }^{\mathrm{e} 5}$ Cognitive impairment may additionally be categorized as single or multiple domain, and as amnestic or nonamnestic, which may help to classify potential subgroups as they relate (1) to biomarkers and pathologic correlates, and (2) to differences in the rate of decline and progression to dementia, each of which may be important in the conduct of clinical trials. A further refinement to describe the cognitive profile of MCI-LB may be provided by using the MDS level II criteria for PD-MCI. ${ }^{15, \mathrm{e} 6, \mathrm{e} 7}$

\section{The cognitive presentation of MCI-LB}

The cognitive pattern of MCI-LB is similar to DLB and typically includes disproportionate attention/executive and visual processing deficits and relatively preserved memory and object naming. ${ }^{16, \mathrm{e} 8, \mathrm{e} 9}$ Impairment on tasks of attention, processing speed, and verbal fluency typically constitute the attention/ executive deficits, and tasks of visual discrimination, assembly, and figure drawing typically constitute the visual perceptual and spatial deficits. ${ }^{5,6,17-19}$

Diagnostic criteria for DLB emphasize that prominent or persistent memory impairment may not necessarily occur in the early stages, ${ }^{2}$ but patients and carers frequently offer memory complaints as a presenting symptom. ${ }^{20}$ Of 49 patients with $\mathrm{MCI}$ who progressed to DLB, $27 \%$ had multidomain amnestic MCI, but only $6 \%$ had single-domain amnestic $\mathrm{MCI}^{3}$ similar to other reports. ${ }^{19,21}$ When patients with MCI-LB have memory impairment, attention and/or visual processing deficits also tend to be present ${ }^{3}$ and may precede the memory difficulties. Patients with RBD who later developed DLB had attention/executive deficits up to 6 years before the diagnosis of dementia and memory deficits up to 2 years before the diagnosis. ${ }^{22}$ The basis for verbal memory impairment in DLB or MCI-LB may be related to slowed processing speed and deficits in working memory and retrieval that characterize the attention and executive deficits, ${ }^{\text {e10 }}$ consistent with hippocampal preservation in MCI-LB compared with MCI-AD. ${ }^{23, \mathrm{e} 11}$ However, impaired memory in DLB may also be related to the extent of coexisting $\mathrm{AD}$-related pathology, ${ }^{\text {e9 }}$ characterized by greater hippocampal atrophy on imaging ${ }^{\mathrm{e} 12}$ and greater CA1 hippocampal subfield pathology on autopsy. ${ }^{\text {e13 }}$ Similar to other subtypes of MCI, a proportion of patients may revert to being cognitively normal, although they remain at a greater risk of the eventual development of dementia. ${ }^{\text {el4 }}$ Some instability of an MCI-LB diagnosis is to be expected given inherent fluctuating cognition, worsening with neuroleptics or anticholinergics, or improvement with levodopa-carbidopa or cholinesterase inhibitors.

In summary, the performance pattern of MCI-LB is best characterized as single- or multidomain nonamnestic MCI, or as multidomain amnestic MCI, whereas single-domain amnestic MCI is more likely to represent MCI-AD. The MCI-LB cognitive pattern is often seen in patients with 1 or more core DLB features, ${ }^{5}$ although these may develop later. ${ }^{3,18}$ Nonamnestic MCI seldom develops into $\mathrm{AD}$ but is associated with a greater risk of transition to $\mathrm{DLB}^{10,21}$ with a ten-fold risk compared with amnestic $\mathrm{MCI}^{3}$ Because a substantial subset of patients with DLB have coexisting $\mathrm{AD}$ related pathology that may influence their cognitive profile, MCI-LB still should be considered an important part of the differential diagnosis in amnestic subjects.

\section{Operationalization of $\mathrm{MCI}-\mathrm{LB}$}

The scheme suggested in table 1 for the identification of MCI-LB allows a diagnosis of either possible or probable MCI-LB based on the number of qualifying clinical features or biomarkers. The terms possible and probable refer to the likelihood of underlying LB disease and not to the MCI syndrome. Structured diagnostic instruments may assist identification of the core clinical features of DLB that precede, coincide with, or follow the onset of cognitive difficulties. ${ }^{24-26}$ Cognitive fluctuations may be of lesser amplitude or frequency than in more severe disease. Passage and sense of presence hallucinatory phenomena may precede the development of recurrent, well-formed and detailed VH. Clinical features supportive of DLB may occur secondary to other causes reducing their diagnostic specificity, but they can be useful indicators of underlying LB disease, particularly when they persist over time or occur in combination.

Use of the possible MCI-LB category may raise diagnostic suspicion prompting further clinical and biomarker investigation. Some possible MCI-LB combinations will likely prove better predictors than others, for example, multidomain nonamnestic MCI plus clinically well-defined RBD is anticipated to be more predictive of progression to DLB than single-domain amnestic MCI plus a history of cognitive fluctuation. The utility of different combinations of clinical features and biomarkers remains to be established.

\section{MCI-LB and PD-MCI}

Uncertainty may occur in deciding how patients exhibiting both MCI and parkinsonism are best categorized. PD-MCI will usually be the most appropriate diagnosis when $\mathrm{PD}$ is diagnosed before significant cognitive decline occurs. The adoption of a 1-year rule similar to that used to separate DLB and PD dementia may be helpful to distinguish some MCI-LB and PD-MCI cases if the onset and order of mild symptoms of parkinsonism and cognitive decline can be clearly established. If not, an initial diagnosis of prodromal LB disease may be preferable, recognizing that this will require revision as the full clinical picture evolves. Individuals with poor global cognitive test performance identified in community samples have been reported to be at a greater risk of developing PD over subsequent years, ${ }^{\mathrm{e} 15, \mathrm{e} 16}$ but poor cognitive test scores are not equivalent to MCI, and this increased risk was no longer statistically significant when individuals with subtle motor signs at baseline were excluded. ${ }^{\mathrm{e} 15}$ There are data to suggest that patients with MCI-LB may have greater cognitive impairment than those with $\mathrm{PD}-\mathrm{MCI},{ }^{27}$ but this is not easily operationalized to differentiate individual subjects. The cognitive deficits of PD-MCI can be heterogeneous, ${ }^{\text {el7 }}$ with 
Table 1 Research criteria for the clinical diagnosis of probable and possible MCI-LB

Essential for a diagnosis of MCI-LB is MCl defined by the presence of each of the following:

Concern by the patient, informant, or clinician regarding cognitive decline.

Objective evidence of impairment in 1 or more cognitive domains. The cognitive impairment may include any domain, but is more likely to be associated with attention-executive and/or visual processing deficits.

Preserved or minimally affected performance of previously attained independence in functional abilities, which do not meet the criteria for dementia.

Core clinical features

Fluctuating cognition with variations in attention and alertness.

Recurrent visual hallucinations.

RBD

One or more spontaneous cardinal features of parkinsonism: these are bradykinesia (defined as slowness of movement and decrement in amplitude or speed), rest tremor, or rigidity.

Proposed biomarkers

Reduced dopamine transporter uptake in basal ganglia demonstrated by SPECT or PET.

Polysomnographic confirmation of REM sleep without atonia.

Reduced meta-iodobenzylguanidine (MIBG) uptake on myocardial scintigraphy.

Probable MCI-LB can be diagnosed if:

Two or more core clinical features of DLB are present, with or without the presence of a proposed biomarker, or

Only 1 core clinical feature is present, but with 1 or more proposed biomarkers.

Probable MCI-LB should not be diagnosed based on biomarkers alone.

Possible MCI-LB can be diagnosed if:

Only 1 core clinical feature of DLB is present, with no proposed biomarkers, or

One or more of the proposed biomarkers is present, but there are no core clinical features.

Supportive clinical features

Severe sensitivity to antipsychotic agents; postural instability; repeated falls; syncope or other transient episodes of unresponsiveness; prolonged or recurrent delirium; autonomic dysfunction, e.g., constipation, orthostatic hypotension, urinary incontinence; hypersomnia; hyposmia; hallucinations in other modalities including passage, and sense of presence phenomena; systematized delusions; apathy, anxiety, and depression.

Potential biomarkers of MCI-LB

Quantitative EEG showing slowing and dominant frequency variability.

Relative preservation of medial temporal lobe structures on structural imaging.

Insular thinning and gray matter volume loss on MRI.

Low occipital uptake on perfusion/metabolism scan.

$\mathrm{MCl}$ plus supportive clinical features or potential biomarkers are insufficient to diagnose MCI-LB but may raise suspicion of it and prompt biomarker investigation and may add weight to an existing MCI-LB diagnosis.

MCI-LB is less likely in the presence of any other physical illness or brain disease including cerebrovascular disease, sufficient to account in part or in total for the clinical picture, although these do not exclude an MCI-LB diagnosis and may serve to indicate mixed or multiple pathologies contributing to the clinical presentation.

Abbreviations: DLB = dementia with Lewy bodies; $\mathrm{MCI}=$ mild cognitive impairment; $\mathrm{MCI}-\mathrm{LB}=\mathrm{MCI}$ with Lewy bodies.

These should be used in conjunction with the corresponding article text, which gives further information about core and supportive clinical features and the use of biomarkers as they apply to MCl-LB.

disproportionately affected attention/executive function, ${ }^{22}$ visuospatial skills, ${ }^{\mathrm{e} 18}$ and memory. ${ }^{28}$ Similar to MCI-LB, there is evidence that nonamnestic $\mathrm{MCI}$ is more common than amnestic MCI and that multidomain amnestic MCI is more common than single-domain amnestic $\mathrm{MCI} .^{29}$

\section{Biomarkers for prodromal DLB}

Direct measures of $\alpha$-synuclein pathology would offer definitive diagnosis at an early stage; several are under development, but none is yet validated or available for use antemortem. Surrogate biomarkers of LB disease must 
therefore be used, as is the case for the diagnosis of DLB itself. $^{2}$ We propose biomarkers for the diagnosis of prodromal DLB, where there is either sufficient, good quality, published evidence of adequate diagnostic specificity in prodromal DLB or this can be reasonably extrapolated from fully developed DLB or related disorders. We categorize biomarkers for which only limited data are available as potential biomarkers, recognizing that such distinctions are likely to require revision as new data become available.

\section{Proposed biomarkers}

\section{Reduced dopamine transporter (DAT) uptake in basal} ganglia demonstrated by SPECT or PET

The utility of DAT imaging in discriminating DLB from $\mathrm{AD}$ is already well established ${ }^{2}$ and its sensitivity in distinguishing MCI with $\mathrm{LB}$ (MCI-LB) from MCI with $\mathrm{AD}$ was $54 \%$ and specificity $89 \%,{ }^{30}$ when MCI-LB was defined by the presence of 1 core clinical feature of DLB in patients with MCI. A higher sensitivity of $61 \%$ was achieved when 2 core clinical symptoms were present. ${ }^{30}$ Reduced striatal DAT uptake therefore seems suggestive of prodromal DLB in a person with MCI, but normal striatal DAT uptake does not exclude it.

\section{Polysomnographic confirmation of REM sleep without atonia}

The association between RBD and synucleinopathy is highly specific, (e.g., a multicenter autopsy study found that of 80 subjects with polysomnography [PSG]-confirmed RBD and a coexisting neurodegenerative disorder, only 2 had a disease unrelated to $\alpha$-synuclein deposition). ${ }^{\mathrm{e} 4}$ These data imply that a patient presenting with $\mathrm{MCI}$ and having PSG-confirmed $\mathrm{RBD}$, that is, a history of probable RBD plus clear documentation of REM sleep without atonia (RSWA) on PSG, also has a high probability of an underlying prodromal synucleinopathy. Because around a quarter of patients with DLB do not report symptoms of RBD and/or have normal REM sleep atonia on PSG, a normal PSG does not exclude a prodromal DLB diagnosis. ${ }^{31}$

\section{Reduced meta-iodobenzylguanidine uptake on myocardial scintigraphy}

Reduced meta-iodobenzylguanidine (MIBG) uptake is an indicative biomarker for $\mathrm{DLB}^{2}$ and has also been reported to occur in a small series of patients with late-onset psychiatric disorder and PSG-confirmed RBD, ${ }^{32}$ reinforcing its association with underlying $\alpha$-synucleinopathy. Of 2 patients with amnestic MCI with low MIBG uptake, one developed DLB after 2 years; the other had no clinical follow-up reported. ${ }^{\text {e19 }}$ $\mathrm{VHs}$ and/or RBD were reported among 7 of 13 patients with MCI with reduced MIBG uptake, the majority of whom also had autonomic symptoms suggestive of LB disease, but they were not followed to determine conversion to DLB. ${ }^{\mathrm{e} 20}$ Despite a paucity of longitudinal data, ${ }^{\mathrm{e} 21}$ there seems to be sufficient evidence that abnormal MIBG myocardial scintigraphy in a patient with $\mathrm{MCI}$ supports a prodromal DLB diagnosis, but further studies are required.

\section{Potential biomarkers}

These are biomarkers consistent with underlying LB disease, which may help the diagnostic evaluation, but for which there is still insufficient evidence of diagnostic sensitivity and specificity in early disease. This will change as new evidence emerges, at which point these, or other candidates, may become considered as indicative of prodromal DLB.

\section{Quantitative EEG showing slowing and dominant frequency variability}

EEG slowing has been reported as predictive of dementia in both $\mathrm{PD}^{\mathrm{e} 22}$ and $\mathrm{RBD},{ }^{\mathrm{e} 23}$ posterior slow wave activity with periodic fluctuations in the pre-alpha range being supportive of DLB. ${ }^{2}$ Quantitative EEG (QEEG) methods show that a dominant frequency $<8 \mathrm{~Hz}$ and dominant frequency variability $>1.5 \mathrm{~Hz}$ is typical of DLB, and in a 3-year, follow-up study, $83 \%$ of subjects with MCI with this pattern at presentation converted to DLB. If these findings are replicated, QEEG may represent a powerful predictor of progression from MCI to DLB. ${ }^{33}$

\section{Relative preservation of medial temporal lobe structures on structural imaging}

Absent or minimal medial temporal lobe atrophy is consistent with DLB, but not sufficiently specific to differentiate it from $\mathrm{AD}^{2}$ Lewy body disease with $\mathrm{RBD}$ is characterized by preserved hippocampal volumes, ${ }^{34}$ and hippocampal preservation in patients with MCI supports progression to DLB instead of $\mathrm{AD}$ dementia with a sensitivity of $85 \%$ and a specificity of $61 \%{ }^{23}$ Suboptimal specificity may be due to the variability of hippocampal atrophy in $\mathrm{AD}^{35}$ and contribution of other pathologic processes such as TAR DNA binding protein 43 (TDP43). ${ }^{\text {e24 }}$

\section{Insular thinning and gray matter volume loss}

Insular cortical thinning occurs in prodromal DLB relative to healthy controls using MRI T1 sequences, with gray matter atrophy predominantly affecting the anterior cingulum and medial frontal structures. This contrasts with more extensive loss of gray matter in the temporal, frontal, and parietal regions of subjects with prodromal $\mathrm{AD}$. Insular cortical thinning may therefore differentiate patients with prodromal DLB not only from healthy controls but also from their prodromal $\mathrm{AD}$ counterparts. ${ }^{36}$ No group differences in insular volumes are seen between $\mathrm{DLB}$ and $\mathrm{AD}$ at the dementia stage, so longitudinal studies are required to determine its precise value as an early diagnostic marker of DLB. ${ }^{37}$ Insula is also involved early in frontotemporal dementia (FTD), being the first cortical area to show atrophy in presymptomatic GRN, MAPT, or C9ORF72 mutation carriers ${ }^{\mathrm{e} 25}$ and unlikely therefore to be helpful in differentiating DLB from FTD.

\section{Low occipital uptake on perfusion/metabolism scan}

Occipital hypometabolism on FDG-PET is associated with $\mathrm{DLB},{ }^{38}$ and together with relative preservation of posterior cingulate metabolism (the cingulate island sign) ) $^{\mathrm{e} 26}$ is a supportive biomarker of DLB. ${ }^{2}$ How frequently the cingulate 
island sign is seen in prodromal DLB remains to be established; significantly reduced posterior cingulate metabolism may be a useful indication of the concurrence of additional neurofibrillary tangle pathology. ${ }^{\text {e27 }}$

\section{Other biomarkers}

There is currently no $\alpha$-synuclein radioligand with sufficient evidence supporting its utility for imaging DLB or any other a-synucleinopathy, nor have any diagnostically applicable biofluid, peripheral tissue, or genotypic biomarkers been established. ${ }^{2}$ CSF measures cannot reliably discriminate between DLB and $\mathrm{AD},{ }^{39}$ although the measurement of CSF $\alpha$-synuclein aggregates using seeding aggregation assays such as protein misfolding cyclic amplification and real-time quaking-induced conversion is providing encouraging preliminary results and may be extended to more accessible biofluids including saliva, plasma, serum, or urine. ${ }^{\text {28 }}$ Combining CSF markers may be useful; for example, addition of CSF phospho-tau to $\alpha$-synuclein significantly improved the differential diagnosis between MCI-LB and MCI-AD increasing sensitivity and specificity both > than $95 \% .{ }^{\text {e29 }}$ Other direct or indirect biomarker candidates that may occur early include identification of phosphorylated $\alpha$-synuclein deposits in peripheral nervous tissue from skin biopsy, ${ }^{40}$ gait analysis, ${ }^{\text {e30 }}$ and abnormalities in color vision discrimination. ${ }^{41,42}$

The figure shows a framework for considering a wider range of biomarkers in the setting of prodromal DLB determining the extent to which $\mathrm{AD}$-related pathology is contributing to the dementia syndrome and influencing clinical trajectories in these patients. ${ }^{43,44, \mathrm{e} 31, \mathrm{e} 32} \mathrm{~A} \beta 42$ declines earlier in $\mathrm{AD}$ than $\mathrm{DLB}$, whereas $\mathrm{A} \beta 40$ levels increase alone in $\mathrm{AD}$. A low
$A \beta 42 / A \beta 40$ ratio may therefore differentiate patients with prodromal $\mathrm{AD}$ from patients with prodromal DLB better than individual measures. ${ }^{43}$ There is also evidence showing different frequencies and topographies of abnormal uptake on amyloid and tau PET imaging in DLB vs $\mathrm{AD} .^{45}$

\section{Delirium-onset DLB}

Cognitive fluctuations, or pronounced variations in alertness and arousal, are a core feature of DLB, apparent as marked fluctuations in cognitive ability or function, detectable by observation or informant report, and measurable using sensitive cognitive and electrophysiologic measures. ${ }^{\text {e33 }}$ The occurrence of delirium (sometimes referred to as acute confusional state) as an early presenting feature of DLB has been described in numerous case reports and series, ${ }^{\text {e34 }}$ including in those with no apparent previous history of cognitive impairment. ${ }^{46, \mathrm{e} 35}$ Whether this represents a greater vulnerability to delirium in subjects with DLB, or the misdiagnosis of severe fluctuations with clouding of consciousness as delirium, or a combination of both is unclear.

Recognition that DLB may first present as delirium is important because most guidelines for behavioral disturbances in delirium recommend antipsychotics as first-line pharmacologic treatment. Delirium or marked fluctuations in consciousness were reported by $43 \%$ of caregivers before DLB diagnosis, ${ }^{47}$ and previous episodes of delirium were much more frequent in patients with DLB compared with patients with $\mathrm{AD}$ ( $25 \%$ vs $7 \%$ ), with 1 in 4 of those with DLB having repeated delirium. ${ }^{11}$ In the majority of these, potential provoking causes were present. A similarly higher incidence of delirium was found for subjects with DLB compared with

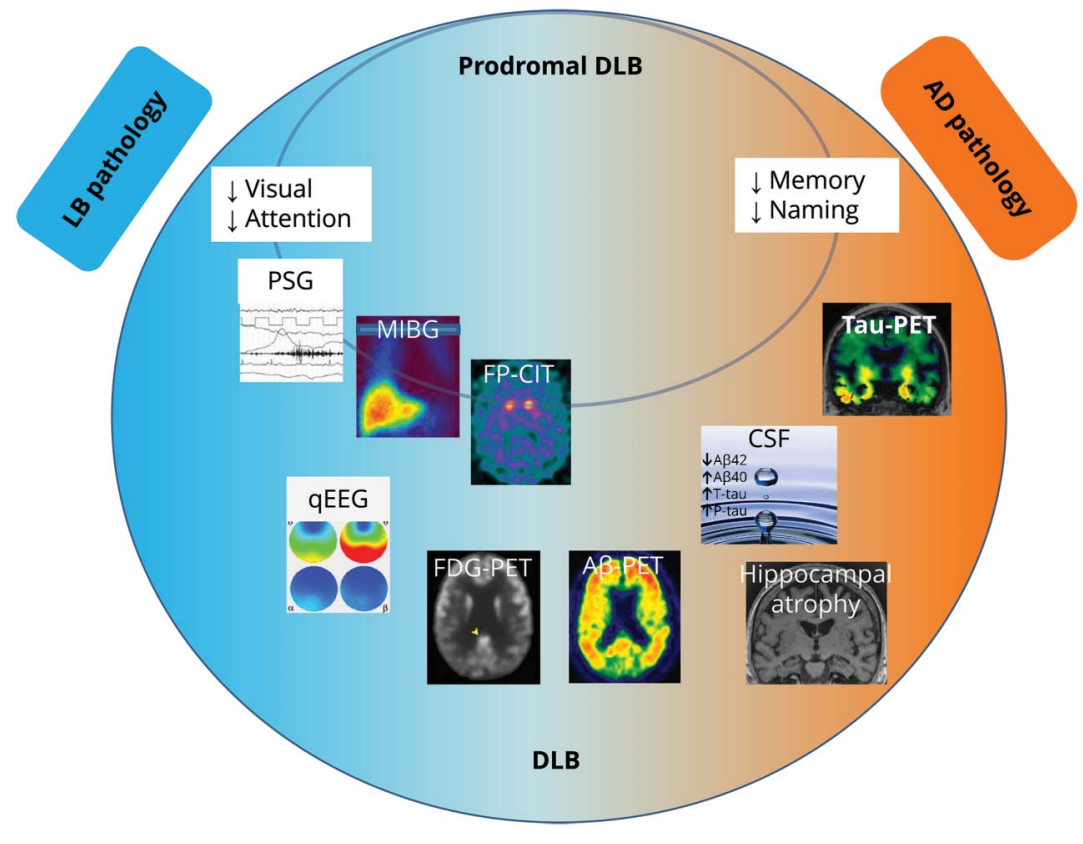

Reduced dopamine transporter uptake in basal ganglia demonstrated by SPECT or PET; PSG-confirmed REM sleep without atonia and MIBG myocardial scintigraphy are proposed as biomarkers of prodromal DLB. Multimodality biomarkers are also important in characterizing patients with prodromal DLB, in whom the pathologic mechanisms of cognitive impairment include both LB and AD pathologies and who may have abnormalities associated with both. Medial temporal lobe uptake on tau PET, medial temporal lobe atrophy on MRI, and high levels of uptake on amyloid PET and positive CSF biomarkers of AD-related pathology may characterize patients with prodromal DLB with significant AD pathology. It is expected that biomarker abnormalities detected in the earliest stages will remain abnormal as disease progresses, with additional biomarkers showing changes later during the progression from prodromal to dementia phase DLB. DLB = dementia with Lewy bodies; MIBG = meta-iodobenzylguanidine. 
subjects with $\mathrm{AD}$ in the year before diagnosis $(17 \cdot 6$ v $3 \cdot 2 / 100$ person-years), ${ }^{9}$ and admissions for delirium were more common in those already diagnosed with DLB than for other dementias. Prolonged delirium may also raise the index of suspicion for DLB. ${ }^{\mathrm{e} 6}$ In an FDG-PET imaging study of prolonged delirium, $32 \%$ of subjects were found to have a DLB like pattern, a high proportion in regard both to the known prevalence of the disease and to that of their matched cognitively impaired control group (4\%). ${ }^{\mathrm{e} 7}$

The similarities between the marked fluctuations in DLB and disturbances of attention and consciousness in delirium have been noted and reviewed, ${ }^{46}$ but there is as yet little understanding of a shared neurobiological basis. There have been few pathologic studies, and although in an epidemiologic-based autopsy cohort, there was no link between delirium and LB pathology at autopsy, ${ }^{\mathrm{e} 38}$ a significantly increased risk of postoperative delirium in those with peripheral $\alpha$-synuclein pathology has been described. ${ }^{48}$ Delirium has been suggested to be more common in those subjects with DLB with later age at onset, ${ }^{\mathrm{e} 39}$ but further evidence is needed.

In summary (table 2), it is clear that DLB can present with delirium, and in patients diagnosed with delirium, a careful search for other DLB features should be made with a low threshold for undertaking DLB biomarker examinations, especially in those with recurrent, unexplained, or prolonged delirium. The extent to which delirium presentations of DLB have the biomarker abnormalities associated with established DLB or other prodromal DLB presentations is unclear, although the PET imaging study cited above supports this, ${ }^{\text {e37 }}$ as does a report of reduced DAT uptake in a patient with acute, unexplained delirium. ${ }^{49}$ The link between delirium and DLB is an important area for future research, to clarify the relationship between the 2 , and to establish which factors associated with delirium should raise the index of suspicion for underlying prodromal DLB.

\section{Psychiatric-onset DLB}

Early clinicopathologic studies suggested that DLB may present as a primary psychiatric disorder, ${ }^{50,51}$ but subsequent focus on the cognitive and motor aspects of DLB has limited the documentation of such cases outside of a few centers. ${ }^{12,32,52-54, e 36}$ Late-onset major depressive disorder and late-onset psychosis are the most frequently reported presentations differing markedly from the construct of mild behavioral impairment ${ }^{\mathrm{e} 40}$ and sometimes sufficiently severe to require hospitalization. Symptoms include hallucinations in visual and in other modalities and systematized delusions including Capgras syndrome, ${ }^{55}$ apathy, anxiety, and depression. Psychiatric-onset DLB cases are not easily differentiated from non-LB late-onset psychosis cases on the basis of primary psychiatric phenomenology or neuropsychological profile alone. ${ }^{54}$ Psychomotor retardation such as slowed speech, thinking, and body movements can resemble the bradykinesia of parkinsonism. The occurrence of rest tremor or rigidity is more helpful than bradykinesia to suspect prodromal DLB in patients with depressive disorder, ${ }^{53}$ but psychotropic-induced parkinsonism may complicate diagnosis. Atypical clinical features may prove valuable pointers

Table 2 Summary of key features of delirium-onset DLB

Patients with DLB are more susceptible to delirium than people with Alzheimer disease, and this delirium may occur as their presenting complaint before dementia develops.

Such episodes may be provoked by multiple factors including surgery, infections/sepsis, fever, or other systemic illness, or secondary to use, or sudden withdrawal of, alcohol or psychoactive drugs.

Prodromal DLB should be particularly suspected in patients

- in whom adequate provoking factors for the delirium are not found.

- with prolonged or recurrent delirium

- who later develop progressive cognitive decline or subsequent dementia

Core clinical features of DLB are likely to be of more limited diagnostic weight in a patient with delirium because

- cognitive fluctuation and clouding of consciousness can also occur in non-DLB delirium, i.e., are not diagnostically specific for DLB in this situation

- visual hallucinations may occur in non-DLB delirium, particularly drug-induced or provoked by alcohol abstinence

- motor parkinsonism present may be due to antipsychotic medications used to treat delirium

- the diagnostic significance of a history of RBD in a person with delirium is not yet established

Identification of delirium-onset DLB

- may be assisted by use of MCI-LB biomarkers, but further research evidence of this is required

- is important to inform the management plan including the avoidance or minimization of antipsychotic and anticholinergic agents

Abbreviations: DLB = dementia with Lewy bodies; $\mathrm{MCI}=$ mild cognitive impairment; $\mathrm{MCI}$-LB = MCI with Lewy bodies; RBD = REM sleep behavior disorder. 
to underlying LB pathology, particularly the presence of recurrent $\mathrm{VH}^{12}$ when these occur before cognitive impairment becomes evident. As with all $\alpha$-synucleinopathies, RBD may be a useful indicator, although a relationship between antidepressant usage and subsequent $\mathrm{RBD}$ onset is a potential confounder. ${ }^{\mathrm{e} 1}$ Although the primary psychiatric manifestations are often accompanied by mild cognitive deficits, ${ }^{54}$ cognitive evaluation and interpretation of performance can be difficult when psychiatric symptoms are prominent. The frequency of cognitive fluctuations in psychiatric-onset LB cases has not been determined.

Initial reports suggest that ${ }^{123}$ I-MIBG scintigraphy may be helpful in psychiatric-onset DLB. ${ }^{52,53,56}$ Eighteen of 35 patients with a first onset of major depressive disorder $>50$ years and with bradykinesia developed a clinical diagnosis of DLB after 6 years of follow-up. All 18 had an abnormal ventilatory response to hypercapnia (VRH), indicative of severe autonomic dysfunction, whereas none of the 17 patients with a normal VRH converted to DLB within the study period. For the converters, the most common presentation was with psychotic and melancholic features simultaneously. The frequency of hypersensitivity to antipsychotics, antidepressants, and antianxiety drugs was higher in converters than in nonconverters. ${ }^{53}$ Further studies need to confirm these findings and to determine the value of other DLB biomarkers in psychiatric-onset cases. ${ }^{32,52,56}$

In summary, it is not yet clear how to identify patients with prominent late-onset psychiatric symptoms who may have underlying LB disease and subsequently progress to DLB. It is premature to try to construct formal criteria for psychiatriconset DLB, but clinicians in mental health and other settings need to be aware that this possibility exists, not least because of the risk of severe antipsychotic sensitivity reactions with increased morbidity and mortality. The small available literature including reports such as those cited above does provide some useful guidance, summarized in table 3 , but requires replication and further investigation.

\section{Idiopathic REM sleep behavior disorder}

$\mathrm{RBD}$ is characterized by abnormal dream enactment behavior during REM sleep, accompanied by loss of muscle atonia during REM sleep (REM sleep without atonia or RSWA) on PSG. For the purpose of a prodromal DLB diagnosis, a clinical history of $\mathrm{RBD}$ is obtained in the same way as for DLB, ${ }^{2}$ that is, a clear complaint of dream enactment by a bedpartner or other witness, with no evidence of sleep disorders that may mimic RBD on clinical interview. Conditions known to mimic or masquerade as RBD include non-REM parasomnias (sleep walking, sleep talking, or other behaviors that emerge from non-REM sleep stages), obstructive sleep apnea, confusional arousals, or nocturnal seizures. In the absence of PSG, the risk of a false-positive clinical diagnosis of RBD is reduced by using optimized sleep questionnaires, which can have sensitivity and specificity over $90 \%$. ${ }^{\mathrm{e} 2}$

RBD may be considered as idiopathic until it is associated with another ongoing neurologic condition, the most frequent being an $\alpha$-synucleinopathy (PD, DLB, or MSA). In a recent large study, $73.5 \%$ of patients with RBD converted to an overt neurodegenerative syndrome after 12 -year follow-up, $56.5 \%$ developing parkinsonism, and $43.5 \%$ dementia as their first

Table 3 Summary of key features of psychiatric-onset DLB

Is characterized by predominant psychiatric symptoms that typically correspond to late-onset major depressive disorder or late-onset psychosis, which may feature hallucinations in visual and in other modalities, and systematized delusions including Capgras syndrome

- may also present with apathy, anxiety, and depression

- may be sufficiently severe to require hospitalization

- the frequency of LB disease as a cause of late-onset psychiatric disorder is not known

When assessing for core clinical features of DLB in a patient with a primary psychiatric presentation:

- bradykinesia may be mimicked by psychomotor retardation, which is commonly seen in depressive disorders

- parkinsonism may be induced by antipsychotic medications used to treat psychiatric disorder

- RBD (and REM sleep without atonia) may be induced by antidepressant medications

- mild cognitive disturbance may be present but is not predominant and may fluctuate

- formal neuropsychological testing may be confounded by the psychiatric mental state

- the frequency and character of cognitive fluctuations is unknown

Identification of psychiatric-onset DLB

- may be assisted by use of MCI-LB biomarkers, but further research evidence of this is required

- is important to inform the management plan including the avoidance or minimization of antipsychotic and anticholinergic agents

Abbreviations: DLB = dementia with Lewy bodies; $\mathrm{MCI}=$ mild cognitive impairment. 
disease manifestation. Among many predictive markers tested, only the cognitive variables differed at baseline between those converting to primary dementia vs parkinsonism. ${ }^{7}$ Other multicenter studies confirm that the only clinical feature that predicts dementia vs parkinsonism first is neuropsychological performance; those with RBD who exhibit cognitive changes are more likely to evolve first into $\mathrm{MCI}$ or DLB. $^{22, e 4}$ Thus, although RBD may be regarded an early manifestation of $\alpha$-synucleinopathy, it is not possible to clearly distinguish whether an individual presenting with RBD will develop dementia first, that is, evolve into a primary DLB diagnosis, or parkinsonism first, that is., a primary $\mathrm{PD} / \mathrm{MSA}$ diagnosis. Any MCI subtype associated with PSG-confirmed $\mathrm{RBD}$ is highly likely to represent underlying LB disease. Although idiopathic RBD is a useful model to study the early stages of LB disease progression, it is not necessarily representative of the whole spectrum of patients with PD and DLB, a significant minority of whom do not have RBD. ${ }^{42}$

\section{Autonomic dysfunction/anosmia and other nonspecific prodromal LB disease symptoms}

Patients with DLB frequently report a history of autonomic dysfunction at first clinic attendance, with $25 \%-50 \%$ complaining of one of more among constipation, orthostatic dizziness, urinary incontinence, erectile dysfunction, increased sweating, or increased saliva. ${ }^{56,57}$ In a cohort of patients with pure autonomic failure, $34 \%$ converted to an overt $\alpha$-synucleinopathy over 6 years of follow-up; this was to DLB (52\%), PD (24\%), or MSA (24\%). ${ }^{58}$ However, because there are many other causes for autonomic dysfunction in older people, these symptoms, either alone or in combination, have low positive predictive value. ${ }^{59}$ The situation is similar for hyposmia, which also frequently occurs early in prodromal DLB and PD, ${ }^{42}$ but which can have many other causes in this age group.

\section{Conclusions and future direction}

Diagnosis of DLB at the dementia stage depends on identifying fully expressed core clinical features, which may be mild or absent at the prodromal stage when biomarker evidence may also be weaker and may even differ from that found at the dementia stage. Several new biomarker candidates, direct and indirect, are in development, and we will continue to review these to update our recommendations as soon as sufficient evidence accumulates. We recognize that the clinical phenotype of neurodegenerative disorders reflects interaction between several rather than a single brain pathology, and it is therefore likely that multiple biomarkers of individual pathologies (e.g., $\alpha$-synuclein, $\beta$-amyloid, and tau), or of disease surrogates (e.g., metabolic imaging/EEG), will be required.

Although we have described the 3 prodromal DLB syndromes separately, they are unlikely to be mutually exclusive, and there may be substantial overlap. We propose operationalized criteria only for MCI-LB because the evidence base from our systematic review, albeit relatively limited, is sufficient to support recommendations that are immediately applicable and testable. Our recommendations should be used alongside guidance about the prodromal manifestations of $\mathrm{PD},{ }^{15,59}$ $\mathrm{MSA}^{60}$ and $\mathrm{AD}^{14}$ with which there is overlap. Notwithstanding the potential benefits of early diagnosis, we are also mindful of the importance of avoiding incorrect (falsepositive) diagnosis of prodromal DLB and the potential negative consequences this could have for an individual. We suggest that the predictive validity of different categories and combinations of our proposed criteria should be clarified by prospective studies before they are adopted for widespread clinical use and that they will enable standardization for inclusion in research studies and clinical trials.

Some published guidance about the early clinical diagnosis of DLB does already exist. DSM5 recommends a diagnosis of mild neurocognitive disorder (NCD) with LB "for individuals who present with the core or suggestive features at a stage when cognitive or functional impairments are not of sufficient severity to fulfill criteria for major NCD". ${ }^{443}$ This is based, however, on the 2005 version of DLB guidelines and requires updating. ICD-11 takes a similar approach toward diagnosing mild NCD at a syndromic level and lists both Lewy body disease and PD as possible causes. ${ }^{\text {e44 }}$

The diagnostic position for other prodromal manifestations of $\mathrm{DLB}$, that is, delirium-onset and psychiatric-onset, is less clear than for MCI. Operationalization of specific criteria for these syndromes is not yet justified, and the reliable differentiation of the minority of delirious and psychiatrically ill patients who have underlying LB pathology, from the majority who do not, will probably only be achieved when routinely applicable biomarkers are developed. LB disease is seldom, if ever, currently considered as part of the differential diagnosis of delirium or late-onset psychiatric disorder, and we hope that the information we provide in the text and accompanying boxes will raise clinicians' awareness of that possibility.

\section{Study funding}

No targeted funding reported.

\section{Disclosure}

I. McKeith receives support from the NIHR Biomedical Research Centre awarded to the Newcastle upon Tyne Hospitals NHS Foundation Trust and Newcastle University and has consulted for GE Healthcare, Sanofi, Eisai, Sumitomo Dainippon Pharma, and Axovant. T. Ferman receives support from NIH P50-AG16574, P30-AG062677, U01-NS100620, and the Mangurian Foundation for Lewy body disease research. A. Thomas receives support from the NIHR Biomedical Research Centre awarded to the Newcastle upon Tyne Hospitals NHS Foundation Trust and Newcastle University and has received grants from GE Healthcare. F. Blanc has served as national clinical trial coordinator for Eisai and Axovant. B. Boeve receives support from NIH P50-AG16574, P30-AG062677, U01-NS100620, and the Mangurian Foundation for Lewy body disease research; has consulted for the Scientific Advisory 
Board-Tau Consortium; and received grants from Biogen, the NIH, the Mangurian Foundation, Alector, the Little Family Foundation, and the Turner Family. H. Fujishiro has received support from Fujifilm RI Pharma Co Ltd. K. Kantarci receives support from NIH P50-AG16574, P30-AG062677, U01NS100620, and the Mangurian Foundation for Lewy body disease research and has received grants from Avid Radiopharmaceuticals and acted on a Data Safety Monitoring Board for Takeda Global Research. C. Muscio acknowledges the support of the Italian Ministry of Health GRANT NET-201102346784. J. O'Brien is supported by the NIHR Cambridge Biomedical Research Centre Dementia and Neurodegeneration and Mental Health Themes and the Cambridge Centre for Parkinson's Plus Disorders; has consulted for TauRx, Axon, GE Healthcare, Eisai, and Avid/Lilly; and received grants from Avid/Lilly and Alliance Medical. R. Postuma has received grants from and consulted for Fonds de la Recherche en Sante; received grants from the Canadian Institutes of Health Research, the Parkinson Society of Canada, the Weston-Garfield Foundation, The Michael J. Fox Foundation, and the Webster Foundation; and consulted for Takeda, Roche/Prothena, Teva Neurosciences, Novartis Canada, Biogen Boehringer Ingelheim, Theranexus, GE Healthcare, Jazz Pharmaceuticals, AbbVie, Jannsen, Otsuko, Phytopharmics, Inception Sciences, and Parkinson Canada. D. Aarsland is a Royal Society Wolfson Research Merit Award Holder and would like to thank the Wolfson Foundation and the Royal Society for their support. He has received research support and/or honoraria from AstraZeneca, H. Lundbeck, Novartis Pharmaceuticals, and GE Health and served as paid consultant for H. Lundbeck, Eisai, Heptares, Sanofi, and Mentis Cura. C. Ballard reports unrelated current grant funding from MRC, Wellcome Trust, European Union, Gillings Foundation, NIHR, Alzheimer's Society, Alzheimer's Research UK, Parkinson's Society, and Lewy Body Society during the conduct of the study and personal fees from Acadia pharmaceutical company, Lundbeck, Roche, Otsuka, Eli Lilly, and AARP outside the submitted work. L. Bonanni is a member of the steering committee of the E-DLB consortium and program chair of the LBD-PIA (ISTAART), and is funded for research on DLB by the Italian Ministry of Health. P. Donaghy receives support from the NIHR Biomedical Research Centre awarded to the Newcastle upon Tyne Hospitals NHS Foundation Trust and Newcastle University. M. Emre served on the scientific advisory board for AC Immune. J. Galvin receives support from NIH grants (R01 AG040211, R01 NS101482, R01 AG057681, and U01 NS100610) and the Lewy Body Dementia Association Research Center of Excellence; reports research support from the NIH, the Lewy Body Dementia Association, The Harry T. Mangurian Foundation, and Albert Charitable Trust; directs clinical trials for Biogen and Novartis; receives licensing fees from Biogen, Roche, Eli Lilly, Quintiles, Roobrik, Continuum Clinical, and Langland; and receives consulting fees from Biogen, Eisai, Bracket, and Medavante. D. Galasko receives support from NIA grant AGO5131 and the Michael J Fox Foundation and has acted as consultant for vTv Pharmaceuticals Inc, Esai, Inc., and for Fujirebio Inc; been a member of a DSMB for Probiodrug, and paid editor for Alzheimer's Research \& Therapy. J. Goldman receives grant/support from The Michael J. Fox Foundation and Parkinson's Foundation and has received consulting fees/honoraria from Acadia, Aptinyx, Sunovion, and Worldwide Med. S Gomperts receives support from NIH grants R01 AG054551, P30AG062421, R01 AG062208, P50 AG005134, R21 NS109833, DOD CDMRP/W81XW1810516, the Farmer Family Parkinson's Initiative, and the Lewy Body Dementia Association and has served on advisory boards for Acadia Pharmaceuticals and Sanofi. L. Honig acknowledges research grant support from NYS CEAD grant C031425, LBDA RCOE, and NIH grants U01NS100600, P50AG008702, R21AG058020, R21MH111596, U01AG051412, U01AG045390, U01AG016976, U01AG023749, U19063893, and U19AG024904. He receives research funding support from AbbVie, Alector, Biogen, Eisai, Genentech, Roche, and Washington University and has received income for consulting for Cortexyme and Eisai. M. Ikeda reports departmental grants and honoraria fees from Sumitomo Dainippon Pharma, Eisai, and Niho Medicine-Physics. J. Leverenz acknowledges support from the National Institutes of Health: P30 AG053762, UO1 NS100610, and R13 NS111954, and Jane and Lee Seidman and Douglas Herthel DVM Memorial Funds and reports consulting fees from Aptinyx, Acadia, Biogen, Eisai, GE Healthcare, Genzyme/Sanofi, and Takeda Pharmaceuticals and grant support from Alzheimer's Drug Discovery Foundation, Department of Defense, GE Healthcare, Genzyme/Sanofi, The Michael J. Fox Foundation, and the NIH (NIA and NINDS). S. Lewis is supported by NHMRC-ARC Dementia Fellows. K. Marder is funded by the NIH: R01NS100600, NS107168, UL1TR001873, and NS073671, with research support from the LBDA, Parkinson Foundation, Michael J. Fox, HDSA, and CHDI, and has acted as site investigator for Vaccinex and Genentech, member of Springer editorial board, and scientific advisory board, Voyager Therapeutics. M. Masellis was supported by a Canadian Institutes of Health Research grant (MOP13129) and an Early Researcher Award from the Ministry of Research, Innovation, and Science (MRIS; ON) and reports personal fees for ad hoc consultancy from Arkuda Therapeutics, Ionis Pharmaceuticals, and Alector Pharmaceuticals, royalties from Henry Stewart Talks Ltd., and grants to the institution from Roche, Novartis, Washington University, and Axovant Sciences. D. Salmon acknowledges support from NIH P30AG062429 and is a paid consultant for Takeda, Inc., Aptinyx, Inc., and Biogen, Inc. J-P. Taylor receives support from the NIHR Biomedical Research Centre awarded to the Newcastle upon Tyne Hospitals NHS Foundation Trust and Newcastle University and reports grants from the UK National Institute of Health Research (NIHR), travel award from Axovant, research support costs from Sonsei-Heptares, and personal fees from GE Healthcare. D. Tsuang acknowledges support from $\mathrm{NIH}$ R21AG064271, R03 NS103950, and U01 NS100610. Z. Walker has been supported by ESRC NIHR (co-app), ARUK (co-app), EU IMI 2 (co-app), and Dunhill Medical Trust. She has received consultancy fees, travel expenses, and research support from GE Healthcare and research support from Life 
Molecular Imaging. P. Tiraboschi acknowledges the support of the Italian Ministry of Health GRANT NET-2011-02346784. Go to Neurology.org/N for full disclosures.

\section{Publication history}

Received by Neurology October 30, 2019. Accepted in final form February 25, 2020.

\section{Appendix Authors}

\begin{tabular}{lll}
\hline Name & Location & Contribution \\
\hline lan G. & Newcastle University & $\begin{array}{l}\text { Design and conceptualization } \\
\text { of the study, acquisition of } \\
\text { McKeith, F }\end{array}$ \\
Med Sci, MD & & $\begin{array}{l}\text { data, analysis and } \\
\text { interpretation of the data, and } \\
\text { drafting and revising the } \\
\text { manuscript for intellectual } \\
\end{array}$ \\
& content.
\end{tabular}

\begin{tabular}{ll}
\hline Tanis J. & Mayo Clinic, \\
Ferman, & Jacksonville \\
PhD &
\end{tabular}

Design and conceptualization of the study, acquisition of data, analysis and interpretation of the data, and drafting and revising the manuscript for intellectual content.

\begin{tabular}{|c|c|c|}
\hline $\begin{array}{l}\text { Alan J. } \\
\text { Thomas, } \\
\text { PhD }\end{array}$ & Newcastle University & $\begin{array}{l}\text { Design and conceptualization } \\
\text { of the study, acquisition of } \\
\text { data, analysis and } \\
\text { interpretation of the data, and } \\
\text { drafting and revising the } \\
\text { manuscript for intellectual } \\
\text { content. }\end{array}$ \\
\hline
\end{tabular}

\begin{tabular}{ll}
\hline Frédéric & University of \\
Blanc, MD & Strasbourg
\end{tabular}

Design and conceptualization of the study, acquisition of data, analysis and interpretation of the data, and drafting and revising the manuscript for intellectual content.

Bradley F. Mayo Clinic, Rochester
Boeve, MD

Design and conceptualization of the study, acquisition of data, analysis and interpretation of the data, and drafting and revising the manuscript for intellectual content.

\begin{tabular}{ll}
\hline Hiroshige & Nagoya University, \\
Fujishiro, & Kawasaki Memorial \\
MD & Hospital
\end{tabular}

Design and conceptualization of the study, acquisition of data, analysis and interpretation of the data, and drafting and revising the manuscript for intellectual content.

\begin{tabular}{|c|c|c|}
\hline $\begin{array}{l}\text { Kejal } \\
\text { Kantarci, } \\
\text { MD, MS }\end{array}$ & Mayo Clinic, Rochester & $\begin{array}{l}\text { Design and conceptualization } \\
\text { of the study, acquisition of } \\
\text { data, analysis and } \\
\text { interpretation of the data, and } \\
\text { drafting and revising the } \\
\text { manuscript for intellectual } \\
\text { content. }\end{array}$ \\
\hline $\begin{array}{l}\text { Cristina } \\
\text { Muscio, PhD }\end{array}$ & $\begin{array}{l}\text { Istituto Neurologico } \\
\text { "Carlo Besta", Milan }\end{array}$ & $\begin{array}{l}\text { Design and conceptualization } \\
\text { of the study, acquisition of } \\
\text { data, analysis and } \\
\text { interpretation of the data, and } \\
\text { drafting and revising the } \\
\text { manuscript for intellectual } \\
\text { content. }\end{array}$ \\
\hline
\end{tabular}

Appendix (continued)

\begin{tabular}{lll}
\hline Name & Location & Contribution \\
\hline $\begin{array}{ll}\text { John T. } \\
\text { O'Brien, F }\end{array}$ & Cambridge University & $\begin{array}{l}\text { Design and conceptualization } \\
\text { of the study, acquisition of } \\
\text { Med Sci, DM }\end{array}$ \\
& $\begin{array}{l}\text { data, analysis and } \\
\text { interpretation of the data, and } \\
\text { drafting and revising the } \\
\text { manuscript for intellectual } \\
\text { content. }\end{array}$ \\
\hline
\end{tabular}

Ronald B. McGill University Design and conceptualization

Postuma, of the study, acquisition of

MD, MSc

data, analysis and

interpretation of the data, and drafting and revising the manuscript for intellectual content.

\begin{tabular}{lll}
\hline Dag & King's College London & Revising the manuscript for \\
Aarsland, & and Stavanger & intellectual content. \\
PhD & University &
\end{tabular}

University
Hospital

\begin{tabular}{lll}
\hline $\begin{array}{l}\text { Clive } \\
\text { Ballard, MD }\end{array}$ & University of Exeter & $\begin{array}{l}\text { Revising the manuscript for } \\
\text { intellectual content. }\end{array}$ \\
\hline $\begin{array}{ll}\text { Laura } \\
\text { Bonanni, } \\
\text { MD, PhD }\end{array}$ & $\begin{array}{l}\text { University of Chieti- } \\
\text { Pescara }\end{array}$ & $\begin{array}{l}\text { Revising the manuscript for } \\
\text { intellectual content. }\end{array}$
\end{tabular}

\begin{tabular}{|c|c|c|}
\hline $\begin{array}{l}\text { Paul } \\
\text { Donaghy, } \\
\text { PhD }\end{array}$ & Newcastle University & $\begin{array}{l}\text { Revising the manuscript for } \\
\text { intellectual content. }\end{array}$ \\
\hline $\begin{array}{l}\text { Murat Emre, } \\
\text { MD }\end{array}$ & $\begin{array}{l}\text { Istanbul Faculty of } \\
\text { Medicine }\end{array}$ & $\begin{array}{l}\text { Revising the manuscript for } \\
\text { intellectual content. }\end{array}$ \\
\hline $\begin{array}{l}\text { James E. } \\
\text { Galvin, MD, } \\
\text { MPH }\end{array}$ & $\begin{array}{l}\text { University of Miami } \\
\text { Miller School of } \\
\text { Medicine }\end{array}$ & $\begin{array}{l}\text { Revising the manuscript for } \\
\text { intellectual content. }\end{array}$ \\
\hline $\begin{array}{l}\text { Douglas } \\
\text { Galasko, MD }\end{array}$ & $\begin{array}{l}\text { University of California, } \\
\text { San Diego }\end{array}$ & $\begin{array}{l}\text { Revising the manuscript for } \\
\text { intellectual content. }\end{array}$ \\
\hline $\begin{array}{l}\text { Jennifer G. } \\
\text { Goldman, } \\
\text { MD, MS }\end{array}$ & $\begin{array}{l}\text { Feinberg School of } \\
\text { Medicine }\end{array}$ & $\begin{array}{l}\text { Revising the manuscript for } \\
\text { intellectual content. }\end{array}$ \\
\hline $\begin{array}{l}\text { Stephen N. } \\
\text { Gomperts, } \\
\text { MD, PhD }\end{array}$ & $\begin{array}{l}\text { Massachusetts General } \\
\text { Hospital }\end{array}$ & $\begin{array}{l}\text { Revising the manuscript for } \\
\text { intellectual content. }\end{array}$ \\
\hline $\begin{array}{l}\text { Lawrence S. } \\
\text { Honig, MD, } \\
\text { PhD }\end{array}$ & $\begin{array}{l}\text { Columbia University } \\
\text { Irving Medical Center }\end{array}$ & $\begin{array}{l}\text { Revising the manuscript for } \\
\text { intellectual content. }\end{array}$ \\
\hline $\begin{array}{l}\text { Manabu } \\
\text { Ikeda, MD, } \\
\text { PhD }\end{array}$ & Osaka University & $\begin{array}{l}\text { Revising the manuscript for } \\
\text { intellectual content. }\end{array}$ \\
\hline $\begin{array}{l}\text { James B. } \\
\text { Leverenz, } \\
\text { MD }\end{array}$ & $\begin{array}{l}\text { Lou Ruvo Center of } \\
\text { Brain Health, Cleveland } \\
\text { Clinic }\end{array}$ & $\begin{array}{l}\text { Revising the manuscript for } \\
\text { intellectual content. }\end{array}$ \\
\hline $\begin{array}{l}\text { Simon J.G. } \\
\text { Lewis, MD }\end{array}$ & University of Sydney & $\begin{array}{l}\text { Revising the manuscript for } \\
\text { intellectual content. }\end{array}$ \\
\hline $\begin{array}{l}\text { Karen S. } \\
\text { Marder, MD, } \\
\text { MPH }\end{array}$ & $\begin{array}{l}\text { Columbia University } \\
\text { Irving Medical Center }\end{array}$ & $\begin{array}{l}\text { Revising the manuscript for } \\
\text { intellectual content. }\end{array}$ \\
\hline $\begin{array}{l}\text { Mario } \\
\text { Masellis, } \\
\text { MD, PhD }\end{array}$ & $\begin{array}{l}\text { Sunnybrook Health } \\
\text { Sciences Centre, } \\
\text { University of Toronto }\end{array}$ & $\begin{array}{l}\text { Revising the manuscript for } \\
\text { intellectual content. }\end{array}$ \\
\hline $\begin{array}{l}\text { David P. } \\
\text { Salmon, PhD }\end{array}$ & $\begin{array}{l}\text { University of California } \\
\text { San Diego }\end{array}$ & $\begin{array}{l}\text { Revising the manuscript for } \\
\text { intellectual content. }\end{array}$ \\
\hline
\end{tabular}


Appendix (continued)

\begin{tabular}{lll}
\hline Name & Location & Contribution \\
\hline $\begin{array}{l}\text { John Paul } \\
\text { Taylor, MB } \\
\text { BS, PhD }\end{array}$ & Newcastle University & $\begin{array}{l}\text { Revising the manuscript for } \\
\text { intellectual content. }\end{array}$ \\
\hline $\begin{array}{l}\text { Debby W. } \\
\text { Tsuang, MD }\end{array}$ & $\begin{array}{l}\text { VA Puget Sound \& } \\
\text { Wniversity of }\end{array}$ & $\begin{array}{l}\text { Revising the manuscript for } \\
\text { intellectual content. }\end{array}$ \\
\hline $\begin{array}{l}\text { Zuzana } \\
\text { Walker, MD }\end{array}$ & $\begin{array}{l}\text { University College } \\
\text { London }\end{array}$ & $\begin{array}{l}\text { Revising the manuscript for } \\
\text { intellectual content. }\end{array}$ \\
\hline $\begin{array}{l}\text { Pietro } \\
\text { Tiraboschi, } \\
\text { MD }\end{array}$ & $\begin{array}{l}\text { Istituto Neurologico } \\
\text { "Carlo Besta", Milan }\end{array}$ & $\begin{array}{l}\text { Design and conceptualization } \\
\text { of the study, acquisition of } \\
\text { data, analysis and } \\
\text { interpretation of the data, and } \\
\text { drafting and revising the } \\
\text { manuscript for intellectual } \\
\text { content. }\end{array}$ \\
& &
\end{tabular}

\section{References}

1. Walker Z, Possin KL, Boeve BF, Aarsland D. Lewy body dementias. Lancet 2015;386: 1683-1697.

2. McKeith IG, Boeve BF, Dickson DW, et al. Diagnosis and management of dementia with Lewy bodies: fourth consensus report of the DLB consortium. Neurology 2017; 89:88-100.

3. Ferman TJ, Smith GE, Kantarci K, et al. Nonamnestic mild cognitive impairment progresses to dementia with Lewy bodies. Neurology 2013;81:2032-2038.

4. Savica R, Bradley BF, Mielke MM. When do alpha-synucleinopathies start? An epidemiological timeline A review. JAMA Neurol 2018;75:503-509.

5. Donaghy PC, Taylor JP, O'Brien JT, et al. Neuropsychiatric symptoms and cognitive profile in mild cognitive impairment with Lewy bodies. Psychol Med 2018;48: 2384-2390.

6. Cagnin A, Bussse C, Gardini S, et al. Clinical and cognitive phenotype of mild cognitive impairment evolving to dementia with Lewy bodies. Dement Geriatr Cogn Dis Extra 2015;5:442-449.

7. Postuma RB, Iranzo A, Hu M, et al. Risk and predictors of dementia and parkinsonism in idiopathic REM sleep behaviour disorder: a multicentre study. Brain 2019;142: 744-759.

8. Sadiq D, Whitfield T, Lee L, Stevens T, Costafreda S, Walker Z. Prodromal dementia with Lewy bodies and prodromal Alzheimer's disease: a comparison of the cognitive and clinical profiles. J Alzheimers Dis 2017;58:463-470.

9. FitzGerald JM, Perera G, Chang-Tave A, et al. The incidence of recorded delirium episodes before and after dementia diagnosis: differences between dementia with Lewy bodies and Alzheimer's disease. J Am Med Dir Assoc 2019;20: 604-609.

10. Jicha GA, Schmitt FA, Abner E, et al. Prodromal clinical manifestations of neuropathologically confirmed Lewy body disease. Neurobiol Aging 2010;31: 1805-1813.

11. Vardy E, Holt R, Gerhard A, Richardson A, Snowden J, Neary D. History of a suspected delirium is more common in dementia with Lewy bodies than Alzheimer's disease: a retrospective study. Int J Geriatr Psychiatry 2014;29:178-181.

12. Fujishiro H, Nakamura S, Sato K, Iseki E. Prodromal dementia with Lewy bodies. Geriatr Gerontol Int 2015;15:817-826.

13. McKeith I, Taylor JP, Thomas A, Donaghy P, Kane J. Revisiting DLB diagnosis: a consideration of prodromal DLB and of the diagnostic overlap with Alzheimer disease. J Geriatr Psychiatry Neurol 2016;29:249-253.

14. Albert MS, DeKosky ST, Dickson D, et al. The diagnosis of mild cognitive impairment due to Alzheimer's disease: recommendations from the National Institute on AgingAlzheimer's Association workgroups on diagnostic guidelines for Alzheimer's disease. Alzheimers Dement 2011;7:270-279.

15. Litvan I, Goldman JG, Tröster AI, et al. Diagnostic criteria for mild cognitive impairment in Parkinson's disease: Movement Disorder Society Task Force guidelines. Mov Disord 2012;27:349-356.

16. Ferman TJ, Smith GE, Boeve BF, et al. Neuropsychological differentiation of dementia with Lewy bodies from normal aging and Alzheimer's disease. Clin Neuropsychol 2006;20:623-636.

17. Cagnin A, Bussè C, Jelcic N, Gnoato F, Mitolo M, Caffarra P. High specificity of MMSE pentagon scoring for diagnosis of prodromal dementia with Lewy bodies. Parkinsonism Relat Disord 2015;21:303-305.

18. Yoon JH, Kim M, Moon SY, Yong SW, Hong JM. Olfactory function and neuropsychological profile to differentiate dementia with Lewy bodies from Alzheimer's disease in patients with mild cognitive impairment: a 5-year follow-up study. J Neurol Sci 2015;355:174-179.

19. Kemp J, Philippi N, Phillipps C, et al. Cognitive profile in prodromal dementia with Lewy bodies. Alzheimers Res Ther 2017;9:19.
20. Auning E, Rongve A, Fladby T, et al. Early and presenting symptoms of dementia with Lewy bodies. Dement Geriatr Cogn Disord 2011;32:202-208.

21. Kondo D, Ota K, Kasanuki K, et al. Characteristics of mild cognitive impairmen tending to convert into Alzheimer's disease or dementia with Lewy bodies: a follow-up study in a memory clinic. J Neurol Sci 2016;369:102-108.

22. Marchand DG, Postuma RB, Escudier F, et al. How does dementia with Lewy bodies start? prodromal cognitive changes in REM sleep behavior disorder. Ann Neurol 2018;83:1016-1026

23. Kantarci K, Lesnick T, Ferman TJ, et al. Hippocampal volumes predict risk of dementia with Lewy bodies in mild cognitive impairment. Neurology 2016;87: 2317-2323.

24. Thomas AJ, Taylor JP, McKeith I, et al. Revision of assessment toolkits for improving the diagnosis of Lewy body dementia: the DIAMOND Lewy study. Int J Geriat Psychiatry 2018;33:1293-1304.

25. Galvin JE. Improving the clinical detection of Lewy body dementia with the Lewy body composite risk score. Alzheimer's Demen (Amsterdam, Netherlands) 2015;1 316-324.

26. Belden CM, Kahlon V, Malek-Ahmadi M, Tsai A, Sabbagh MN. Clinical character ization of mild cognitive impairment as a prodrome to dementia with Lewy bodies. Am J Alzheimers Dis Other Demen 2015;30:173-177.

27. Yoon JH, Lee JE, Yong SW, Moon SY, Lee PH. The mild cognitive impairment stage of dementia with Lewy bodies and Parkinson disease A comparison of cognitive profiles. Alzheimer Dis Assoc Disord 2014;28:151-155

28. Fengler S, Liepelt-Scarfone I, Brockmann K, Schäffer E, Berg D, Kalbe E. Cognitive changes in prodromal Parkinson's disease: a review. Mov Disord 2017;32:1655-1666.

29. Kalbe E, Rehberg SP, Heber I, et al. Subtypes of mild cognitive impairment in patients with Parkinson's disease: evidence from the LANDSCAPE study. J Neurol Neurosurg Psychiatry 2016;87:1099-1105.

30. Thomas AJ, Donaghy P, Roberts G, et al. Diagnostic accuracy of dopaminergic imaging in prodromal dementia with Lewy bodies. Psychol Med 2018:1-7.

31. Ferman TJ, Boeve BF, Smith GE, et al. Inclusion of RBD improves the diagnostic classification of dementia with Lewy bodies. Neurology 2011;77:875-882.

32. Fujishiro H, Okuda M, Iwamoto K, et al. Early diagnosis of Lewy body disease in patients with late-onset psychiatric disorders using clinical history of rapid eye movement sleep behavior disorder and I-123 -metaiodobenzylguanidine cardiac scintigraphy. Psychiatry Clin Neurosci 2018;72:423-434.

33. Bonanni L, Perfetti B, Bifolchetti S, et al. Quantitative electroencephalogram utility in predicting conversion of mild cognitive impairment to dementia with Lewy bodies. Neurobiol Aging 2015;36:434-445.

34. Murray ME, Ferman TJ, Boeve BF, et al. MRI and pathology of REM sleep behavior disorder in dementia with Lewy bodies. Neurology 2013;81:1681-1689.

35. Murray ME, Graff-Radford NR, Ross OA, Petersen RC, Duara R, Dickson DW. Neuropathologically defined subtypes of Alzheimer's disease with distinct clinical characteristics: a retrospective study. Lancet Neurol 2011;10:785-796.

36. Blanc F, Colloby SJ, Cretin B, et al. Grey matter atrophy in prodromal stage of dementia with Lewy bodies and Alzheimer's disease. Alzheimers Res Ther 2016;8:31.

37. Blanc F, Colloby SJ, Philippi N, et al. Cortical thickness in dementia with Lewy bodie and Alzheimer's disease: a comparison of prodromal and dementia stages. Plos One 2015;10:e0127396.

38. Surendranathan A, O’Brien JT. Clinical imaging in dementia with Lewy bodies. Evid Based Ment Health 2018;21:61-65.

39. Outeiro TF, Koss DJ, Erskine D, et al. Dementia with Lewy bodies: an update and outlook. Mol Neurodegener 2019;14:5.

40. Donadio V, Incensi A, Rizzo G, et al. A new potential biomarker for dementia with Lewy bodies Skin nerve alpha-synuclein deposits. Neurology 2017;89: 318-326.

41. Flanigan PM, Khosravi MA, Leverenz JB, Tousi B. Color vision impairment differentiates Alzheimer dementia from dementia with Lewy bodies. J Geriatr Psychiatry Neurol 2018;31:97-102.

42. Fereshtehnejad SM, Yao C, Pelletier A, Montplaisir JY, Gagnon JF, Postuma RB. Evolution of prodromal Parkinson's disease and dementia with Lewy bodies: a prospective study. Brain 2019;142:2051-2067.

43. Bousiges O, Bombois S, Schraen S, et al. Cerebrospinal fluid Alzheimer biomarkers can be useful for discriminating dementia with Lewy bodies from Alzheimer's disease at the prodromal stage. J Neurol Neurosurg Psychiatry 2018;89:467-475.

44. Kantarci K, Lowe VJ, Boeve BF, et al. Multimodality imaging characteristics of dementia with Lewy bodies. Neurobiol Aging 2012;33:2091-2105.

45. Kantarci K, Lowe VJ, Boeve BF, et al. AV-1451 tau and beta-amyloid positron emission tomography imaging in dementia with Lewy bodies. Ann Neurol 2017;81 $58-67$.

46. Gore RL, Vardy E, O’Brien JT. Delirium and dementia with Lewy bodies: distinct diagnoses or part of the same spectrum? J Neurol Neurosurg Psychiatry 2015;86: $50-59$.

47. Aarsland DS, Auning E. The pre-dementia stage of dementia with Lewy bodies. Eur J Neurol 2011;18:69.

48. Sunwoo MK, Hong JY, Choi J, Park HJ, Kim SH, Lee PH. alpha-Synuclein pathology is related to postoperative delirium in patients undergoing gastrectomy. Neurology 2013;80:810-813.

49. Akintade O, Pierres F. Acute presentation of dementia with Lewy bodies. Clin Med 2019;19:327-330.

50. Kosaka K. Diffuse Lewy body disease in Japan. J Neurol 1990;237:197-204.

51. Birkett DP, Desouky A, Han L, Kaufman M. Lewy bodies in psychiatric patients. Int J Geriatr Psychiatry 1992;7:235-240. 
52. Kobayashi K, Nakano H, Akiyama N, Maeda T, Yamamori S. Pure psychiatric presentation of the Lewy body disease is depression - an analysis of 60 cases verified with myocardial meta-iodobenzylguanidine study. Int J Geriatr Psychiatry 2015;30:663-668.

53. Takahashi S, Mizukami K, Arai T, et al. Ventilatory response to hypercapnia predicts dementia with Lewy bodies in late-onset major depressive disorder. J Alzheimers Dis 2016;50:751-758.

54. Van Assche L, Van Aubel E, Van de Ven L, Bouckaert F, Luyten P, Vandenbulcke M. The neuropsychological profile and phenomenology of late onset psychosis: a crosssectional study on the differential diagnosis of very-late-onset Schizophrenia-like psychosis, dementia with Lewy bodies and Alzheimer's type dementia with psychosis. Arch Clin Neuropsychol 2019;34:183-199.

55. Thaipisuttikul P, Lobach I, Zweig Y, Gurnani A, Galvin JE. Capgras syndrome in dementia with Lewy bodies. Int Psychogeriatr 2013;25:843-849.
56. Fujishiro H, Iseki E, Nakamura S, et al. Dementia with Lewy bodies: early diagnostic challenges. Psychogeriatrics 2013;13:128-138.

57. Chiba Y, Fujishiro H, Iseki E, et al. Retrospective survey of prodromal symptoms in dementia with Lewy bodies: comparison with Alzheimer's disease. Dement Geriatr Cogn Disord 2012;33:273-281.

58. Kaufmann H, Norcliffe-Kaufmann L, Palma JA, et al. Natural history of pure autonomic failure: a United States prospective cohort. Ann Neurol 2017;81:287-297.

59. Heinzel S, Berg D, Gasser T, et al. Update of the MDS research criteria for prodromal Parkinson's disease. Mov Disord 2019;34:1464-1470.

60. Palma JA, Norcliffe-Kaufmann L, Kaufmann H. Diagnosis of multiple system atrophy. Auton Neurosci 2018;211:15-25.

Data available from Dryad (Additional References, References e1-e44): doi:10.5061/ dryad.1c59zw3rv

\section{Subspecialty Alerts by E-mail!}

Customize your online journal experience by signing up for e-mail alerts related to your subspecialty or area of interest. Access this free service by clicking on the "My Alerts" link on the home page. An extensive list of subspecialties, methods, and study design choices will be available for you to choose from-allowing you priority alerts to cutting-edge research in your field!

\section{COVID-19 and Neurologic Disease: Call for Papers!}

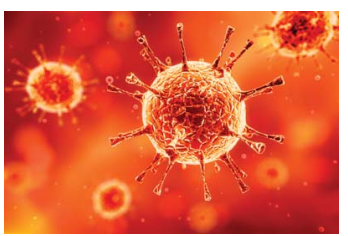

The editors of Neurology are interested in papers that address the neurological aspects of COVID-19 infection and challenges to the management of patients with chronic neurological conditions who have, or are at risk for, the infection. Relevant papers that pass initial internal review will undergo expedited peer review and online publication. We will consider papers posted in preprint servers.

Submit observational studies and clinical trials as Articles and case series and case reports under the Clinical/Scientific Notes category to https://submit.neurology.org/ today!

\section{Visit the Neurology ${ }^{\circledast}$ Website at Neurology.org/N}

- More article-based content on home pages

- Streamlined menus and navigation

- Enhanced blog sections for specialty areas

- $\quad$ Same experience on desktop, tablet, and mobile devices

- Improved article reading experience; links more evident (pdf, analytics, social media)

- Neurology ${ }^{\circledR}$ Clinical Practice initiative "Practice Current" global surveys will be accessible across sites

f Find Neurology ${ }^{\circledR}$ on Facebook: http://tinyurl.com/neurologyfan

Follow Neurology ${ }^{\circledR}$ on Twitter: https://twitter.com/GreenJournal 


\section{Neurology}

\section{Research criteria for the diagnosis of prodromal dementia with Lewy bodies}

Ian G. McKeith, Tanis J. Ferman, Alan J. Thomas, et al.

Neurology 2020;94;743-755 Published Online before print April 2, 2020

DOI 10.1212/WNL.0000000000009323

This information is current as of April 2, 2020

\section{Updated Information \& Services}

References

Citations

Subspecialty Collections

Permissions \& Licensing

Reprints including high resolution figures, can be found at: http://n.neurology.org/content/94/17/743.full

This article cites 59 articles, 12 of which you can access for free at: http://n.neurology.org/content/94/17/743.full\#ref-list-1

This article has been cited by 2 HighWire-hosted articles: http://n.neurology.org/content/94/17/743.full\#\#otherarticles

This article, along with others on similar topics, appears in the following collection(s):

\section{Delirium}

http://n.neurology.org/cgi/collection/delirium

Dementia with Lewy bodies

http://n.neurology.org/cgi/collection/dementia_with_lewy_bodies

MCI (mild cognitive impairment)

http://n.neurology.org/cgi/collection/mci_mild_cognitive_impairment Parkinson's disease with dementia

http://n.neurology.org/cgi/collection/parkinsons_disease_with_dementi a

Psychosis

http://n.neurology.org/cgi/collection/psychosis

Information about reproducing this article in parts (figures,tables) or in its entirety can be found online at:

http://www.neurology.org/about/about_the_journal\#permissions

Information about ordering reprints can be found online:

http://n.neurology.org/subscribers/advertise

Neurology ${ }^{\circledR}$ is the official journal of the American Academy of Neurology. Published continuously since 1951, it is now a weekly with 48 issues per year. Copyright Copyright ( 2020 The Author(s). Published by Wolters Kluwer Health, Inc. on behalf of the American Academy of Neurology.. All rights reserved. Print ISSN: 0028-3878. Online ISSN: 1526-632X.

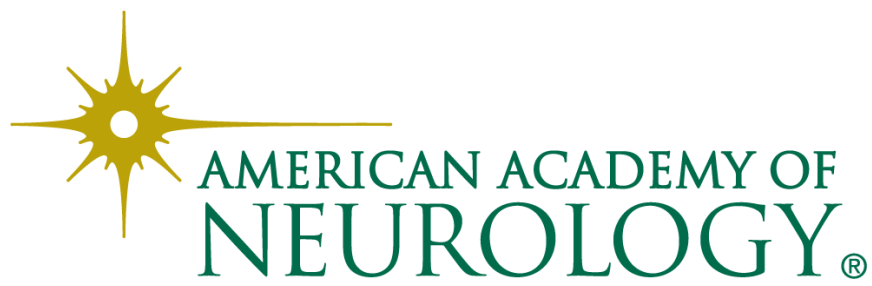

